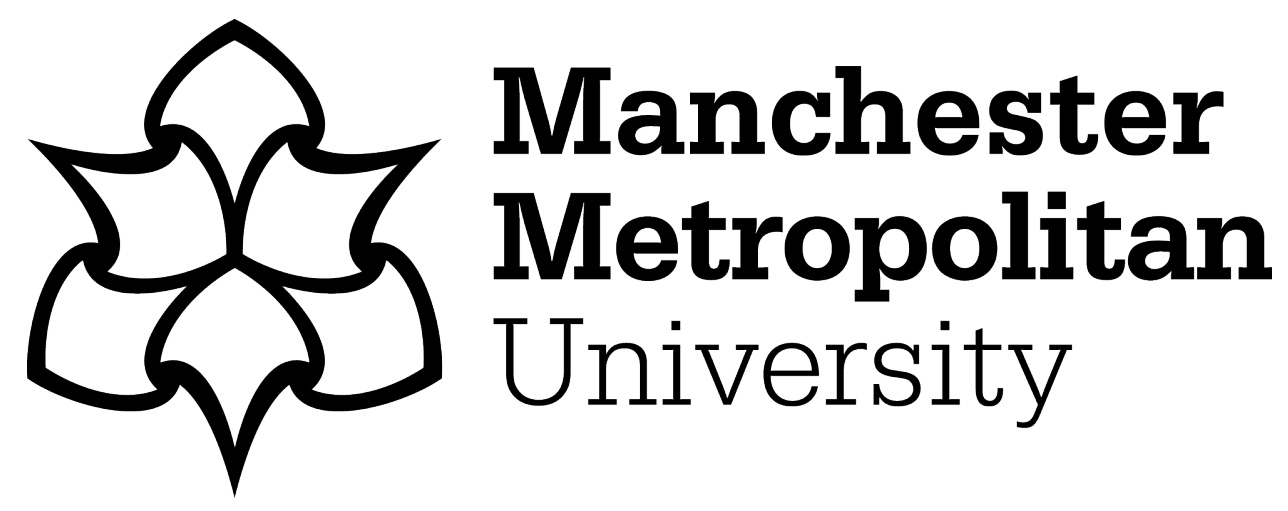

Veer Ramjeawon, Poonam and Rowley, Jennifer ORCID logoORCID: https://orcid.org/0000-0003-3437-6914 (2020) Enablers and Barriers to Knowledge Management in Universities: Perspectives from South Africa and Mauritius. Aslib Journal of Information Management, 72 (5). pp. 745-764. ISSN 2050-3814

Downloaded from: https://e-space.mmu.ac.uk/625759/

Version: Accepted Version

Publisher: Emerald

DOI: https://doi.org/10.1108/AJIM-12-2019-0362

Please cite the published version 


\title{
Enablers and Barriers to Knowledge Management in Universities: Perspectives from South Africa and Mauritius
}

\begin{abstract}
Purpose: Universities need to manage their knowledge assets, and, to work creatively to maximise the enablers and minimise the barriers associated with knowledge management processes. This research offers a comparative perspective on knowledge management in universities in two countries whose university sectors are at different stages of their development, South Africa and Mauritius.

Design/methodology/approach: Semi-structured interviews were conducted with expert informants from thirteen high-ranking universities in Mauritius and South Africa, who held senior roles in research and its management within their respective universities

Findings: Both enablers and barriers (e\&bs) were evident in relation to: strategies and policies, organisational structures, rewards and incentives, culture, technology, leadership, human resources, resources and funding, and university-industry linkages, although the significance of these e\&bs varied between the three knowledge processes, knowledge creation, knowledge sharing, and knowledge transfer. Overall, Mauritius, with a less developed university sector, faced more challenges in respect of knowledge management than did South Africa.

Originality/value: This study's theoretical contribution is a holistic framework for enabling KM in universities on the basis of a mapping between $\mathrm{KM}$ e\&bs and KM processes. This comparative country level study, embracing a number of universities, offers insights into national policy, and cultural expectations that influence the extent and nature of barriers and enablers to effective KM. The insights offered by this study will be valuable for Mauritius and South Africa, and also for universities in other countries.
\end{abstract}

Keywords: Knowledge management, Knowledge creation, Knowledge sharing, Knowledge transfer, Universities, Research. 


\section{Introduction}

Sub-Saharan Africa (SSA), with a population of about 1.078 billion, is one of the poorest regions in the world, despite a population growth rate of around 2.7\% (World Bank, 2018). The population of SSA is expected to double by 2050 to around 2.4 billion. Nevertheless, the region holds enormous economic potential that might be realised through reforms that boost its competitiveness, including human capacity building. Human capacity building can be achieved by developing the knowledge sector; globally, universities are considered as a key driver for a knowledge-based economy and have considerable potential to act as an engine of economic growth and development. It is imperative that the knowledge created by SSA's universities is used to drive innovation. However, universities face a wide range of challenges, including the emergence of the knowledge society, the globalization and internationalization of universities, reduced budgets and government support, increased enrolment at undergraduate level, and, widening access. Effective knowledge management (KM) practices will help universities to improve their efficiency and effectiveness, to be more competitive, and to contribute to the wealth of their country (Alexandropoulou et al., 2009; Fussy, 2018).

Universities are involved in the knowledge management processes of knowledge creation, sharing and transfer (Alexandropoulou et al., 2009; Adhikari, 2010; Fullwood et al., 2013). Whether or not universities have an explicit knowledge management strategy (Cranfield and Taylor, 2008; Trivella and Dimitrios, 2015), it is important that they manage their knowledge assets, and, in particular, that they understand and work creatively with the enablers and barriers associated with knowledge management processes. Whilst previous studies have reported on enablers and barriers to knowledge management (Arntzen et al., 2009; Tian et al., 2009; Ramachandran et al., 2013), none has performed a comparative study at country level. Hence, this study embraces a number of universities in two countries, South Africa and Mauritius, to offer insights into national policy, and the cultural expectations that influence the extent and nature of barriers and enablers. More specifically, this paper aims to: (a) identify and compare the perceived enablers and barriers to knowledge creation, sharing and transfer in universities in the two countries; (b) to propose a conceptual framework for embedding KM in universities; and, (c) to offer unique insights into knowledge creation, sharing and transfer in the under-researched sector of Sub-Saharan 
universities. This will act as a basis for recommendations for improving knowledge management effectiveness in research environments in universities worldwide.

In this study, knowledge management (KM) in universities is regarded as having three main strands, knowledge creation, knowledge sharing, and knowledge transfer as these KM processes are closely linked to the three missions of universities (teaching, research and service to society). To fulfil these three missions, universities globally create knowledge through research, share knowledge through teaching and learning, and transfer knowledge to the society through consultancies, a trained workforce, cross pollination between research and business, communication, popularization of science, and job creation through spin-offs (Rowley, 2000; Alexandropoulou et al., 2009; Adhikari, 2010; Fullwood et al., 2013; Ramachandran et al., 2013). Despite the significant research interest in the KM processes in universities, very few previous studies on $\mathrm{KM}$ in universities have covered all three $\mathrm{KM}$ processes, knowledge creation, knowledge sharing, and knowledge transfer.

\section{Literature review}

\subsection{Knowledge management in universities}

Universities create knowledge through research, share knowledge through teaching and learning and transfer knowledge to the society through consultancies and a trained workforce (Rowley, 2000; Adhikari, 2010; Ramachandran et al., 2013). On the other hand, previous research has demonstrated that universities often do not have an explicit KM strategy nor an institution-wide approach to KM, and, even if they are aware of the importance of such a strategy, it is difficult to implement (Cranfield and Taylor, 2008; Trivella and Dimitrios, 2015). It is, therefore, important to be aware of the enablers and barriers associated with KM processes, such as knowledge creation, knowledge sharing and knowledge transfer in universities. 


\subsection{Previous research on Enablers and barriers to knowledge management in universities}

Previous studies have revealed several enablers (factors enhancing KM) and barriers (factors having an adverse effect on KM). Many of these factors can have either a positive or a negative impact on KM processes, such as knowledge creation, knowledge sharing, and knowledge transfer. The most often identified factors include culture, rewards and incentives, technology, leadership, organisational structures, and university-industry linkages. A few studies have also identified the importance of strategies and policies, human resources, and resources and funding. In this section, the order of factors is broadly in accordance with the attention that they have received in previous research.

Culture has been the most extensively researched enabler or barrier for KM implementation in universities (Cranfield and Taylor, 2008; Ramachandran et al., 2013). Culture has been shown to effect: knowledge creation (Siadat et al., 2012); knowledge sharing (Arntzen, et al., 2009; Tian et al., 2009; Goh and Sandhu, 2013); and, knowledge transfer (Gera, 2012; Torre et al., 2018). However, culture is complex and difficult to control in KM implementation (Cranfield and Taylor, 2008). Some researchers suggest that the culture in universities is individualistic, and to some extent, self-serving (Tian et al., 2009; Fullwood et al., 2013) and that academics prefer to work independently (Goh and Sandhu, 2013). On the other hand, other researcher have demonstrated that a strong knowledge sharing culture can enhance KM processes, such as knowledge creation (Tian et al., 2009; Gera, 2012).

Rewards and incentives. In universities, the embedded and international reward structure places a high value on evidence of individual achievement in research and scholarship (Rowley, 2000). This poses a challenge for universities who need to create incentives that recognize academics' contributions to knowledge sharing systems (Arntzen et al., 2009; Gill, 2009). Academics engage in knowledge sharing and appreciate the opportunity to improve and extend their relationships with colleagues through knowledge sharing. However, they also view working with others as generating opportunities for internal promotion and career development elsewhere in the sector (Fullwood et al., 2013). Similarily, reward and recognition systems are needed that incentivize innovative work practices and knowledge sharing with external organizations (Gera, 2012). 
Recently, Torre et al. (2018) suggested that weak incentives for researchers to transfer knowledge to society is a barrier to successful engagement in KT.

Technology is viewed as an enabler for KM (Arntzen et al., 2009; Gill, 2009; Adhikari, 2010; Ramachandran et al., 2013), and its processes, knowledge creation (Tian et al., 2009; Supapawawisit et al., 2018) and knowledge sharing (Fullwood et al., 2013). Appropriate information and communication technologies can help universities to move towards a knowledgebased learning organization, if they can achieve a 'good fit' between information technology (IT), socio-organizational factors, and a sustainable organizational culture (Arntzen et al., 2009; Gill 2009; Adhikari 2010). In Bangkok University, development of knowledge sharing structures such as, knowledge repositories, collaborative tools and emails-forum-chat-video have been used to facilitate knowledge sharing (Arntzen et al., 2009). Information Technology was found to be one the most extensively used KM enablers in public universities in Malaysia (Ramachandran et al., 2013) and in Thailand (Supapawawisit et al., 2018). However, in a UK-based study, academics were neutral with regard to the importance of technology, possibly due to their high level of autonomy (Fullwood et al., 2013).

Leadership or top management support is an important driver of KM (Twum-Darko and Harker, 2015). Previous studies have examined the role of leadership in HE for developing knowledgebased organizations, and to support KM and knowledge sharing (Gill, 2009; Fullwood et. al., 2013). Most studies have concluded that leaders can play an important role in initiating KM (Gill, 2009; Ramachandran et al., 2013). However, Fullwood et. al. (2013) did not find leadership to be central to knowledge sharing and Supapawawisit et al. (2018) found it to be the least critical factor for research and innovation in public universities in Thailand.

Organizational structure is also important for effective KM (Rowley, 2000; Adhikari, 2010; Eftekharzade and Mohammadi, 2011), and its processes, knowledge creation (Supapawawisit et al., 2018), knowledge sharing (Arntzen et al. 2009; Fullwood et al., 2013) and knowledge transfer (Fuller et al., 2019). Adhikari (2010) advocates the importance of both formal (physical layout of offices) and informal (communities of practice) organisational structures to facilitate social interaction. 
University-industry linkages can facilitate knowledge transfer and stimulate production of new knowledge. However, KT requires time and space to develop a shared understanding, nurture relationships and identify mutual interests amongst partners (Gertner et al., 2011). Guimón (2013) identifies the inherent mismatch between the research orientations of firms and universities and their focus on different outputs (e.g. new products vs publications) as barriers to KT. Universities in developing countries generally face greater challenges in such alliances, because they look to the Government to provide the overall framework for developing these linkages, through the formulation of policy directions and reward systems (Bano and Taylor, 2014). Also, the linkages between universities and industry are often informal and weak (Zavale and Macamo, 2016) due to lack of time, insufficient internal capability to manage relationships, and difficulty in identifying partners (Hughes and Kitson, 2012). In developed countries, these linkages emerge from incentivising universities' KT activities (Rossi and Rosli, 2015).

Strategies and polices reflect the individual universities' vision and mission, and national policy perspectives regarding knowledge creation, sharing and transfer (Cloete and Bunting, 2013; Hewitt-Dundas, 2012). Clear and effective policy directions are necessary to strengthen research capacities and enhance knowledge production and technological innovation (Cloete and Bunting, 2013; Fussy, 2018). According to Fuller et al. (2019), government policies in the UK need to be re-evaluated to ensure that they drive third stream activities, which promote knowledge transfer from universities for economic impact, through innovation and entrepreneurship.

Human resource has received limited attention as a facilitator of KM in universities (Gill, 2009; Eftekharzade and Mohammadi, 2011; Gera, 2012; Supapawawisit et al., 2018). On the other hand, human resource management is a critical driver of research and innovation creation in public universities in Thailand (Supapawawisit et al., 2018). Gera (2012) is also of the view that human resource management, supported by IT and KM, can minimize or eliminate knowledge transfer gaps, leading to improved competitiveness and performance.

Resources and funding have received very limited attention, although a recent study found financial resources to be the most critical factor for enhancing research and innovation in public 
universities in Thailand (Supapawawisit et al., 2018). However, previous studies have found that lack of resources, including lack of time, is a key impediment to knowledge sharing (Arntzen et al., 2009) and knowledge exchange (Hughes and Kitson, 2012). No past study has identified funding as either an enabler or a barrier to KM in HE.

More generally, the relationship between KM processes and enablers in the context of universities has received very limited attention. A recent conceptual KM model proposed (but not tested) by Ojo (2016) for Nigerian universities incorporates five KM processes (knowledge identification/creation, storage, sharing, application, and evaluation), that are supported by six key enablers (organisational culture, leadership, information technology, reward mechanisms, social capital, and performance measurement). This model has some parallels with Rivera and Rivera (2016)'s empirically tested KM model for Mexico, which includes four KM processes (knowledge creation, storage, transference, and application) and six enablers (leadership, culture, structure, human resources, information technologies, and measurement). These studies conclude that KM processes can be facilitated through a set of KM enablers, leading to improvements in performance, research processes, research outputs, teaching and learning, administrative processes, curriculum planning, and societal impact.

\subsection{Research gap and contribution}

The majority of studies have been conducted in countries with well-developed university systems, such as the UK (Cranfield and Taylor, 2008; Rossi and Rosli, 2014; Fuller et al., 2019) and Malaysia (Ramachandran et al., 2013; Goh and Sandhu, 2013). Hence, there is a knowledge gap in relation to countries with developing and aspirational university sectors, such as several of the countries in the sub-Saharan African region.

The majority of previous studies on enablers and barriers for effective KM in universities have examined only one or two factors focussing on either knowledge creation, knowledge sharing or knowledge transfer (Gera, 2012; Fullwood et al., 2013; Ramachandran et al., 2013). In past studies, culture, reward and incentives, and technology were found to be prominent factors impacting knowledge sharing and knowledge creation in universities (Arntzen et al., 2009; 
Fullwood et al., 2013; Supapawawisit et al., 2018). Very few previous studies have investigated factors such as, strategies and policies (Cloete and Bunting, 2013; Fussy, 2018), human resources (Eftekharzade and Mohammadi, 2011) and resources and funding (Hughes and Kitson, 2012) in relation to KM in HE. In addition, only Ojo (2016) and Rivera (2016) have proposed conceptual models of KM processes and enablers. No previous study has explored more than six factors whilst specifically considering the three KM processes (knowledge creation, knowledge sharing and knowledge transfer).

\section{Methodology}

\subsection{Research Context}

This study adopted case study as the research strategy, defined by Yin (2014 p.16), as "an empirical inquiry that investigates a contemporary phenomenon (the "case") in depth and within its realworld context, especially when the boundaries between the phenomenon and context may not be clearly evident". By undertaking a comparative study, this research addressed the deficit associated with country-level comparative studies on knowledge management in HEI's. Mauritius and South Africa, two of the most competitive economies in the sub-Saharan region, were chosen as the case study sites on account of their geographical proximity, and shared aspiration to be the most competitive and innovative country in the Sub-Saharan African region, and because very few past studies on knowledge management in HEIs have been reported in Sub-Saharan Africa.

According to the Global Competitiveness Report (GCR), 2019, Mauritius ranks 52 ${ }^{\text {nd }}$ and South Africa at $60^{\text {th }}$ out of the 141 countries, which participated in the survey in 2019. In the sub-Saharan African region, Mauritius is ranked first and South Africa second (GCR, 2019, p. ix), although on innovation capability, South Africa is second, whilst Mauritius is third. On the other hand, according to the Times Universities World University Ranking (2020), nine South African universities are amongst the Top 30 African Universities, including the top four universities, whereas none of the Mauritian universities are listed. Two of South Africa's universities appears in the top 200 of the worldwide rankings out of 1,400 universities across 92 countries; South Africa is the only country in Africa with a university in the top 500. According to UNESCO 2017 statistics, the Gross Tertiary Enrolment rate (GTER) for Mauritius (41\%) is higher than that for 
South Africa (22\%), however, the Gross Domestic Expenditure on Research and Development (GERD) as a percentage of GDP was higher for South Africa (0.8\%) than for Mauritius ( $0.4 \%)$.

According to the Council of Universities website (http://www.che.ac.za/focus_areas/higher_education_data/2013/overview), South Africa has 26 public institutions, including eleven universities, six universities of technology, eight regional "comprehensive" universities (established through the merger of a technical higher education institution and a university), and one health sciences university for a population of about 57.5 million. The university sector also includes 124 private higher education institutions. In Mauritius, there are 55 institutions, including four public universities and six public and 45 private institutions (Higher Education Commission (HEC), (http://www.tec.mu/overview) for a relatively small population of about 1.3 million. Most of the private institutions are small institutions (Cloete and Maassen, in: Muller et al., 2017: 101) involved in providing franchising programmes of awarding bodies based either locally or overseas or both; many are either branches of or affiliated with overseas institutions from, for example, Australia, India, South Africa, and the UK.

\subsection{Research approach}

In selecting the universities to be included in this research, the key criteria were: the research ranking and productivity of the university (with high being preferred), engagement with knowledge management processes, and the willingness of staff with an appropriate research-based portfolio to participate.

The study used interviews with expert informants from thirteen high-ranking universities in Mauritius and South Africa, all of whom held senior roles in research and its management within their respective universities. Qualitative research using semi-structured interviews that sought to generate in-depth insights was deemed appropriate (Saunders et al., 2019). Furthermore, the study adopted an interpretivist stance that was inductive in nature. Purposive sampling was conducted, in which participants were selected on the basis of recommendations from university vicechancellors. This purposive sampling approach gave good access to interviewees 'who are in a position to answer the questions and to provides the insights that the researcher was seeking' 
Rowley (2012, p. 264). Meetings were planned to suit the convenience of the busy interviewees' schedules.

An interview schedule was designed, and piloted through meetings with three senior academics (two professors (former deans) and one Director General (equivalent to Vice Chancellor), all with extensive experience in research and research management. Heads of institutions were contacted in order to obtain approval to interview them or their senior colleague(s). Prior to each interview, the researcher provided interviewees with information on the study, the interview guide, and knowledge management terminology and definitions to facilitate discussion. Permission to record each interview was obtained through a consent form. Participation was voluntary and interviewees were informed that interviews and any documents provided during and after the interview were confidential; interviewees were free to decline to answer any questions or to withdraw from the interview at any time. The interviews lasted between 45 minutes and an hour.

In Mauritius, face-to-face interviews were conducted with eleven senior managers and academics holding research and innovation portfolios, including Director Generals, heads of faculty, heads of academics (equivalent to Pro-VCs), and senior academics and researchers from four public and three private universities. These seven universities in Mauritius are amongst the top HEIs in Mauritius. In South Africa, Skype interviews were preferred due to travel constraints. In Skype interviews, the interviewee and interviewer are in a virtual face-to-face situation (Rowley, 2012). During the Skype interviews, interviewees were willing to share information and reported that they found the research area to be relevant and interesting. In South Africa, interviews were conducted with eight senior managers involved in research and/or research and innovation management, including Deputy Vice-Chancellor, Pro Vice-Chancellor, Directors of Research, Innovation and Post-Graduate Studies from six public universities, all of which are amongst Top 30 universities in the country and in Africa (Table 1). All interviews were recorded using a handheld recorder. The information obtained was verified with information available online and through documents provided by the participants. 
Each interview was transcribed verbatim into Microsoft Word and interview transcripts were reviewed and coded. Transcription helped in familiarization with the data. The next step was data reduction through thematic analysis. Summary notes were made to facilitate the identification of patterns and themes in the study data (Miles and Huberman, 1994). Next, data display, including drawing out insights by using comparative tables, was conducted. During the data reduction stage, the authors worked with Word documents. Although the analysis was guided by the themes in the interview schedule, it was not restricted to them. An inductive approach was used to confirm the initial list of enablers and barriers drawn from the literature, and to develop a mapping between these and the $\mathrm{KM}$ processes, $\mathrm{KC}$, $\mathrm{KS}$ and $\mathrm{KT}$, as a basis for undertaking a comparison between the two countries.

Table 1: Participant Profile

\begin{tabular}{|c|c|c|c|}
\hline $\begin{array}{l}\text { Country/ } \\
\text { Type of } \\
\text { Institution }\end{array}$ & $\begin{array}{l}\text { Institution } \\
\text { number }\end{array}$ & $\begin{array}{l}\text { Participant } \\
\text { Code }\end{array}$ & Brief description of participants \\
\hline \multirow{4}{*}{$\begin{array}{l}\text { Public } \\
\text { Universities }\end{array}$} & 1 & $\begin{array}{l}\text { M-A1 } \\
\text { M-A2 } \\
\text { M-A3 }\end{array}$ & $\begin{array}{l}\text { Three senior academics and researchers at } \\
\text { Associate Professor and Professor level, former } \\
\text { Heads of Departments and Heads of Faculties }\end{array}$ \\
\hline & 2 & $\begin{array}{l}\text { M-B1 } \\
\text { M-B2 } \\
\text { M-B3 }\end{array}$ & $\begin{array}{l}\text { Acting Director General } \\
\text { Head of Faculty } \\
\text { Academic researching in KM }\end{array}$ \\
\hline & 3 & $\mathrm{M}-\mathrm{C}$ & Head of Faculty \\
\hline & 4 & M-D & Director General \\
\hline South Africa & 1 & SA-A & $\begin{array}{l}\text { Deputy Vice-Chancellor: Research, Innovation } \\
\text { and Technology }\end{array}$ \\
\hline \multirow[t]{2}{*}{$\begin{array}{l}\text { Public } \\
\text { Universities }\end{array}$} & 2 & $\begin{array}{l}\text { SA-B1 } \\
\text { SA-B2 }\end{array}$ & $\begin{array}{l}\text { Executive Director Research and Innovation } \\
\text { Senior Director: Postgraduate School }\end{array}$ \\
\hline & 3 & $\begin{array}{l}\mathrm{SA}-\mathrm{C} 1 \\
\mathrm{SA}-\mathrm{C} 2\end{array}$ & $\begin{array}{l}\text { Director, Innovation Office } \\
\text { Director of Research Capacity Development }\end{array}$ \\
\hline
\end{tabular}




\begin{tabular}{|l|l|l|l|}
\hline 4 & SA-D & $\begin{array}{l}\text { Pro-VC Innovation, Commercialisation and } \\
\text { Entrepreneurship }\end{array}$ \\
\cline { 2 - 4 } & 5 & SA-E & Assistant Director Research Data Management \\
\cline { 2 - 4 } & 6 & SA-F & Director e-Research \\
\hline
\end{tabular}

\section{Findings}

\subsection{Introduction}

Findings are reported under each of the clusters of knowledge management processes, knowledge creation (KC), knowledge sharing (KS) and knowledge transfer (KT). For each of KC, KS and KT participants' views on the enablers and barriers (e\&bs), as identified from the literature are reported. In each section $(4.2,4.3$, and 4.4), e\&bs are discussed in the same order, but not all e\&bs are evident in each of $\mathrm{KC}, \mathrm{KS}$ and $\mathrm{KT}$, such that the number of e\&bs shown under each section varies between sections. Within sections, comments from universities in Mauritius and from universities in South Africa are compared. The mapping between e\&bs and knowledge management processes (KC, $\mathrm{KS}$, and $\mathrm{KT})$ is summarised in Figure 1.

\subsection{Enablers and Barriers to Knowledge Creation}

\section{Strategies and policies}

In comparison to Mauritius where interviewees suggested that there was a lack of policies to promote knowledge creation through research, South Africa has numerous strategies and policies to encourage knowledge creation (including a research policy and strategy, and a policy on contract management).

We don't have a clear-cut policy encouraging people to focus on research. (M-B2)

We have a research policy and a strategic document on research, innovation and community engagement plus a specific policy on contracts management. (SA-A) 
However, South Africa's policy to increase the enrolment rates in universities, which was leading to 'massification of education' and its link to 'input subsidy' from the government poses a barrier to academics and researchers.

Most South African universities have taken on more and more students for financial reasons because we get a government subsidy based on the number of students we register. Most universities have succumbed to that pressure at the cost of research activities. (SAF)

\section{Organisational structures}

In South Africa, the presence of dedicated structures, such as the National Research Foundation (NRF), and Research Offices in universities were regarded as enabling knowledge creation.

One of the biggest supporters of research and innovation in South Africa is the NRF. (SAB2)

We have three offices, which together make up a virtual research office. (SA-C2)

South African participants reported on the range of facilities provided to academics and researchers through the research office, such as, databases, laboratories and support in identifying research grants, drafting proposals and managing the entire research process through IT-based platforms (SA-F).

We make available the databases, shared laboratories, virtual laboratories, and virtual databases, that are required for knowledge creation. (SA-A)

The public universities in South Africa also have research chairs and research centres to promote research and knowledge creation.

We have six research centres where new knowledge is produced from research and where post-graduate research is carried out. (SA-A)

Specific structures for knowledge storage such as institutional repositories and library services are also available.

We have the institutional repository and the open access platform to disseminate research outputs or published articles. (SA-F)

Mauritian participants also regarded libraries as an enabler, and some commented on the development of digital libraries. 
Knowledge created is stored in files, books, libraries, journals papers, theses, committee minutes, and reports generated in the university. Nowadays, most of it is stored electronically. (M-A1)

\section{Rewards and incentives}

Most of the participants from public universities in Mauritius mentioned incentives that encourage knowledge creation, such as, sponsorships to attend conferences, both locally and overseas, and grants to staff to upgrade their qualifications. Some universities also encouraged their academics to participate in exchange programmes with overseas institutions. However, lack of reward mechanisms to support knowledge creation through research was considered as a barrier to knowledge creation.

The staff development scheme provides opportunities for academic staff to upgrade their credentials, to present their research papers overseas and to work with laboratories and share expertise with another colleague. (M-A2)

I believe if you want research and innovation, you need to have a policy framework that rewards research and innovation (M-B1).

On the other hand, academics and researchers in South African universities benefit from several awards, rewards and incentives. Participants mentioned a number of awards that acknowledged academics' contribution to research and innovation, including: researcher of the year, innovator of the year, emerging researcher of the year, at both faculty and institutional level, and lifetime achievement awards at national level.

We have the 'researcher of the year and the 'innovator of the year' awards (SA-C1)

Every year the institution rewards the researcher of the year and the emerging researcher of the year [...] at the faculty level and the institution level. Our NRF together with our Department of Science and Technology have national awards as well [....] lifetime achievers award, young achievers' awards for young people who show immense promise as a scientist (SA-C2).

In addition, output subsidies are monetary rewards and incentives to encourage academics and researchers to engage in research and knowledge creation. The funding is used to develop research, 
attend conferences or buy equipment. High impact research outputs by academics and researchers are considered as key indicators of their performance, ultimately leading to promotion

We have monetary incentives; we give a small amount to the academics for their career development [....] It gives a feeling of a direct reward over and above the salary [....] they use that money wisely. (SA-A)

We have a Performance Management System (PMS), which looks at all academic's performance and one of the key performance indicators for academics is research outputs [...] it's kind of a way to incentivize them monetarily. Also the promotions policy document has a heavy weighting towards knowledge generation and knowledge dissemination and research. Also, we have a research publication award annually to incentivize the researchers $(S A-D)$.

Accreditation as a 'NRF rated' researcher is another major incentive for South African academics/researchers to undertake high quality research and publish in high impact journals.

We have a system of accreditation through the $N R F$, level $A, B, C$, it is a research standing based on peer-review. It puts an academic in a position to qualify for funding from the $N R F$. $(S A-A)$

Such accreditation helps researchers to position themselves as leaders in their field, which helps in attracting national and international funds and collaboration for research, which, in turn, supports the universities in positioning themselves as research-intensive institutions and lifting their ranking.

\section{Leadership}

Compared to Mauritius, where lack of vision and frequent changes in leadership was reported by participants, the university leadership in South Africa was considered as committed and visionary.

We are in a phase where we do not have any topmost management. (M-C)

In the last five years, the university has witnessed change in leadership three times. (MA1)

The reason why we are so far ahead of any other university in this country is because the leadership at the university is committed to supporting research in the $21^{\text {st }}$ century, it is making huge investments in systems that support the research process. (SA-F) 
All the participating universities in South Africa had dedicated leaders, such as, Pro VCs or Deputy VCs for research and innovation and commercialisation, while in Mauritius, with the exception of one university, where a Pro VC had research portfolio, most institutions had only more junior heads of research.

\section{Human resources}

Mauritian participants reported having qualified and experienced academics in public universities and were proud of their expertise.

We have the highest number of PhDs of any university in Mauritius. Of 42 full time staff, 21 have PhDs. (M-B1)

We have a lot of expertise, but then the question is that how do you harness that expertise $(M-A 2)$.

South African participants felt that there should be more academics with PhDs. Their government is addressing this issue through policy measures by increasing the percentage of $\mathrm{PhD}$ qualified staff in the higher education sector from the current $34 \%$ to over $75 \%$ by 2030 (NDP, 2030).

Only $45 \%$ of our staff have doctorates, so clearly that is one challenge that we are working on. We are trying to get all our staff to enrol for higher degrees. (SA-B2)

In addition, there was a paucity of experts in areas pivotal to knowledge management, such as data managers, infrastructure managers, data scientists, and project management.

The challenge is in terms of skills and competencies of data managers and infrastructure managers. Also [...] As soon as we train them, they go out to the industry and earn more money. $(S A-F)$

Many academics are not used to managing big research and innovation projects. They may be good at research but lack project management skills (SA-C1).

To facilitate knowledge creation, research offices in South African universities organise research capacity development, including workshops and training on writing proposals, research supervision, and mentoring of young academics by retired and senior academics.

We have programmes to develop research capacity, such as workshops on research supervision, and on how to write proposals (SA-C1) 
We have a special programme for post-retirement re-appointments specifically of seasoned academics who mentor the younger academics, it is one of the management interventions" $(S A-A)$.

\section{Resources and funding}

Time was the resource that was most under pressure. This was due to heavy teaching loads and administrative duties, which impeded high quality research and knowledge creation in both Mauritius and South Africa.

We are expected to carry a heavy teaching load, heavy administration load, heavy student counselling, and interaction load. We are expected to do service, that is consulting [...] you're probably holding down a family life. Somewhere all of that does not add up. Unfortunately, this is [....] probably leading to seeking out publishing opportunities in less than honourable publications and paying to get published. (M-A3)

Academics and researchers and innovators are spending a significant amount of their time in undergraduate teaching and it does not leave time for any kind of research and innovation. $(S A-D)$

In Mauritius, lack of funding for research was a major challenge for most participants. Lack of funding results in limited investment in, for example, well-equipped laboratories for research and development.

We have budgetary constraints. We have very big visions, but we do not have the resources to realise these visions. (M-C)

On the other hand, South African universities receive input and output subsidies from the government through the NRF, which are linked to funding received for student enrolment (input subsidy) and research outputs (output subsidy) in high-indexed journals by academics and researchers of the institution (SA-A).

We get a huge amount of funding, we get about 250 Million Rand (Approx. 15 Million USD) a year, through the NRF; that is a big enabler of research in South Africa. (SA-B2)

Nevertheless, South African participants found the funding environment to be very competitive. Even though some funding is available, it takes a lot of time, and is not guaranteed, due to the competitive environment. (SA-C1) 
Table 2 summarises the enablers and barriers to knowledge creation in universities. In Mauritius, lack of strategies and policies, leadership, and resources and funding were considered to be barriers to $\mathrm{KC}$, whilst organisational structures and rewards and incentives, were identified as both enablers and barriers. Human resources were considered to be an enabler. In South Africa, organisational structures, rewards and incentives, and leadership were enablers for $\mathrm{KC}$, and strategies and policies, human resources, and resources and funding, were deemed to be both enablers and barriers to $\mathrm{KC}$.

[Insert Table 2 here]

\subsection{Enablers and Barriers to Knowledge Sharing}

\section{Rewards and incentives}

Participants from both Mauritius and South Africa reported a lack of incentives for knowledge sharing among peers, even though the staff exchange programme with overseas universities was identified in South Africa as an enabler to knowledge sharing (SA-E).

There are no incentives, no encouragement from the system to promote sharing and collaboration. (M-A1)

I don't think there are any incentives or any encouragement to share (SA-D)

In South Africa, national bodies, such as the NRF also promote collaboration and sharing across institutions through their calls for proposals.

\section{Culture}

A lack of a knowledge sharing culture due to the promotion policy (rewarding individual achievements rather than involvement in multi-disciplinary and inter-institutional research projects), leads to individualistic and competitive behaviour that provokes mistrust, fear, and selfishness in Mauritius.

Culture wise, there is a problem. People tend to be individualistic; there is reluctance to share knowledge. This is also linked to our promotion exercise, which does not give weight to collaboration and sharing. (M-A1) 
South African participants also reported an academic culture that promotes turf protection, individualistic behaviour, and a silo mentality amongst academics.

Some people are very protective over their territory and would not easily share (SA-B1).

There is some resistance to knowledge sharing because people feel that they lose their competitive edge once it is out in the public domain, and somebody can piggyback on their ideas (SA-C2).

If organisational structure within disciplines and within departments doesn't encourage trans-disciplinary and cross-disciplinary research, it could lead to a lack of knowledge sharing and collaboration and promote working in silos (SA-C1).

Knowledge sharing is an academic cultural issue [...] historically, academics were encouraged to work as individuals and the most sharing that ever happened was between a supervisor and his/her research group [...] There is also some resistance to knowledge sharing because people feel that they lose their competitive edge once it is out in the public domain. $(S A-C 2)$

Nevertheless, knowledge sharing in South African universities is prevalent at discipline, inter and intra institutional, and national and international level. Academics are also encouraged to form multidisciplinary and transdisciplinary collaborations as a basis for bidding for funding opportunities. However, academics' initial loyalty is towards their discipline; institutions try to leverage on this by forming research groups around specific research themes.

We encourage multidisciplinary and transdisciplinary groups and provide funding to enrich their research programmes [...] Academics are required to have collaborators both internally (within the department and within the faculty and university) and nationally and internationally. This is part of the university's strategy to raise visibility. There are also several group funding opportunities, which require a group or a consortium to bid; this has led many people to work together. (SA-B1)

Researchers tend to congregate in disciplines and their initial loyalty is to their discipline rather than to their institution. So we (at the e-research office) try to capitalise on this. (SA-F) 
Knowledge sharing through networking and international partnerships and collaborative efforts around a 'community of practice' and participating in virtual research environments were also reported by participants in South Africa.

We are part of a very prestigious group of international universities. And there is a lot of sharing and common activities going on. Our University is the first and only African University to be invited to join one of the most prestigious and innovative university consortia in the world, the Universitas 21 (https://universitas21.com) [....]. Over the last two years, our university has established a programme called 'Global Excellence and Stature Programme' [....] bringing together distinguished visiting Professors and topnotch international researchers at the University, postdoctoral students and postgraduate students ...to build collaboration with different international partners (SA-B2).

We are setting up a centre called 'Future Africa' for transdisciplinary science leadership for innovation. We want to draw people from across Africa to build leadership in science, build networks between leaders of science across Africa and develop interdisciplinary and multi-disciplinary research teams. The centre will develop expertise across Africa through transdisciplinary research partnerships across numerous disciplines with the cooperation of international and African scholars $(S A-E)$.

In Mauritius, the culture of involvement in multi-disciplinary and inter-institutional research projects requires further development. On the other hand, in South Africa, the environment is highly competitive due to increasing knowledge production, accreditation of academics and researchers by the National Research Foundation, and the race for higher ratings and rankings.

\section{Technology}

Both Mauritian and South African universities have adequate IT infrastructure and connectivity for knowledge sharing among peers. In addition, South African researchers commented on access to open access platforms and institutional repositories; neither of these were not mentioned by researchers in Mauritius.

We have a good information technology system at the university, and we have just implemented a new database management system (M-A1)

Technology is not an issue for us. (SA-C1) 


\section{Leadership}

Frequent changes in leadership was found to be a deterrent in creating a knowledge sharing culture in Mauritius. However, this was not reported in South Africa.

Earlier, under our Head of Institution, every month we were having knowledge sharing sessions, but for the time being this is not continuing as we are in a phase where we do not have any top management. $(M-C)$

Table 2 summarises the enablers and barriers to knowledge sharing in universities of the two countries. In Mauritius, lack of rewards and incentives, knowledge sharing culture, and frequent changes in leadership were viewed as barriers to KS. In South Africa, rewards and incentives, as well as culture, were regarded as both enablers and barriers to KS. IT infrastructure was an enabler in both countries.

\subsection{Enablers and Barriers to Knowledge Transfer}

\section{Strategies and policies}

South African universities have intellectual property policies to encourage knowledge transfer; these are absent in Mauritius.

We have an Intellectual Property policy, which talks about commercialisation. (SA-C1) Furthermore, the government of South Africa passed the Intellectual Property (IPR) Act in 2008 to promote knowledge transfer. The IPR Act requires every university in South Africa to have a Technology Transfer Office. However, participants from South Africa were of the view that the IPR Act is also a deterrent to knowledge transfer.

One of the problems in South Africa in the last few years is that there has been the 'Intellectual Property Act', which means that universities are now becoming more protective of the knowledge that they have created, and how they transfer it. (SA-D)

\section{Organisational structures}

In comparison to Mauritius, where there was a lack of structures to promote knowledge transfer, the South African universities, by the virtue of IPR Act (2008), were encouraged to create 
appropriate structures. These included Technology Transfer Offices or Intellectual Property Units within their research offices, to promote and encourage knowledge transfer and provide support for contract research, patenting and commercialisation of research results.

We have not organized our knowledge at the university [through, for instance, a web portal] so that it can be transferred, and people can access it. (M-A1)

We have an office dedicated to support academics and researchers in the patenting process, the Technology Transfer Office. (SA-F)

Furthermore, the IP Units and/or Technology Transfer office (TTOs) in South Africa were also mandated to create awareness campaigns and training programmes for industry.

We (TTO) run several awareness campaigns on what constitutes Intellectual Property (IP); we bring in an IP Attorney during lunch-time workshops. (SA-C1)

We have our commercial arm or company 'Enterprises' where we provide all kinds of short courses, training, and expertise to industry. (SA-E)

However, a participant in South Africa mentioned a lack of information amongst academics and researchers on patenting processes.

There is a lack of information or misinformation about how the patenting process works. We still have academics that believe that a patent is equal to an embargo on releasing information, which is not so [....] they can still publish as long as they've put in their application to patent, but that's something that is not clearly understood in our institution $(S A-C 2)$.

\section{Rewards and incentives}

Both Mauritian and South African universities have financial incentives to support knowledge transfer. However, in Mauritius, there was no uniform policy for the sector, although there were various incentives, such as financial benefits, or a reduced teaching load.

If the staff bring in consultancies, they are paid. (M-B1)

In South Africa, if the knowledge transferred through the technology transfer office is successfully commercialised, the inventors get a financial incentive.

If knowledge is transferred through the technology transfer office, in the event of a successful commercialisation, researchers get $30 \%$ of the benefits. (SA-C1) 


\section{University-industry linkages}

In South Africa, the government, through the NRF, has launched mechanisms to encourage university-industry linkages.

Our NRF have a programme called 'THRIP' (The Technology and Human Resources for Industry Programme) which is about research with industry partnerships [...] where industry partners are expected to submit the application. (SA-C2)

In addition, incubators to encourage partnerships with industry were in evidence.

An important innovation from the Innovation Office is an incubator, which encourages partnerships with industry partners. (SA-C2)

Despite these measures, participants were of the view that the level of technology transfer and technology linkages in South African universities is still at a low level compared to that in other countries.

In terms of innovation, technology transfer and patents, we are certainly not at the same level as Singapore or other places, so that continues to be a challenge [....] Singapore and China have close relationships between industry, government and the universities. Here, industry-university linkages have not been made. (SA-B2)

Similarly, in Mauritius, knowledge transfer with industry is limited to a few public universities, due to weak university-industry linkages, and the absence of a dedicated knowledge transfer office in most universities. Knowledge transfer is restricted to organising tailor-made courses and CPDs.

Table 2 summarises the enablers and barriers to knowledge transfer in universities in the two countries. In Mauritius, lack of strategies and policies and organisational structures were viewed as barriers to knowledge transfer, while in South Africa, these two factors were viewed as both enablers and barriers. Financial incentives were found to be an enabler for KT in both countries, but weak university-industry linkages were regarded as a barrier in both countries.

\subsection{Enabling Knowledge Management in Universities Framework}

The insights outlined above form the basis for the proposal of the 'Embedding Knowledge Management in Universities Framework' (Figure 1). The framework summarises the central tenet of this study, that knowledge management processes (knowledge creation, knowledge sharing, and 
knowledge transfer) are both facilitated and constrained by a wide range of KM enablers and barriers. These include: strategies and policies, organisational structure, rewards and incentives, culture, technology, leadership, human resources, resources and funding, and university-industry linkages. This research also reveals that the extent of the impact of these e\&bs varies both between universities, and between the three knowledge management processes included in this study. For example, the following six factors either facilitate or inhibit knowledge creation: strategies and policies; organisational structures; rewards and incentives; leadership; human resources; and, resources and funding. Four factors enable or hinder knowledge sharing: rewards and incentives; culture; technology; and, leadership. Knowledge transfer is facilitated or hindered by: strategies and policies; organisational structures; rewards and incentives; and, university-industry linkages. [Figure 1]

\section{Discussion}

In past studies, culture, reward and incentives, technology, leadership, and organisational structures were found to be prominent factors impacting knowledge sharing and knowledge creation in universities (Arntzen et al., 2009; Supapawawisit et al., 2018). As in previous studies (Tian et al., 2009; Fullwood et al., 2013), in Mauritius, lack of a knowledge sharing culture was perceived as a barrier, whereas in South Africa, culture was identified as a barrier as well as enabler. South Africa had dedicated structures (Adhikari, 2010; Fuller et al., 2019) and numerous rewards, awards and incentives to promote knowledge creation (Supapawawisit et al., 2018), sharing (Kim and Ju, 2008), and transfer (Rossi and Rosli, 2015); these initiatives may contribute to the high ranking of South African universities in the region. Universities in both countries had adequate IT infrastructure and connectivity for knowledge sharing, although South Africa had institutional repositories and open access platforms as enablers, which were lacking in Mauritius. Evidence from Malaysia and Thailand also confirms IT to be critical for enhancing research and innovation (Ramachandran et al., 2013; Supapawawisit et al., 2018).

Lack of strategies and policies were regarded as barriers in Mauritius, whereas South Africa had numerous strategies and policies to promote knowledge creation, sharing and transfer (as also 
reported by Cloete and Bunting, 2013; Fussy, 2018). Lack of visionary leadership and frequent changes in top leadership were seen as barriers to creating a culture for knowledge creation and sharing in Mauritius. On the other hand, dedicated and committed leaders were regarded as key enablers for enhancing research, innovation and commercialisation in South Africa. These findings identify top management support as one of most important drivers of KM (Twum-Darko and Harker, 2015) and that leaders can play an important role in initiating KM (Ramachandran et al., 2013).

Mauritian participants reported having qualified and experienced academic staff, but South African participants suggested that the absence of sufficient staff with a $\mathrm{PhD}$ was a barrier to future development. Other studies have also reported that human resource is a vital factor (Eftekharzade and Mohammadi, 2011). In particular, consistent with earlier studies, lack of resources, such as time, was a barrier for all three processes in both countries (Arntzen et al., 2009; Hughes and Kitson, 2012). University-industry linkages were perceived as weak in both countries. Similar findings were reported from Mozambique (Zavale and Macamo, 2016), another sub-Saharan African country.

\section{Conclusion and recommendations}

Compared to South Africa, Mauritius has fewer enablers and more barriers to KM. Nevertheless, despite being leaders in the region, South African universities also face numerous challenges, which arise from the increasing demand for universities in the country. This study proposes a holistic framework for enabling KM in universities, which summarises the relationship between $\mathrm{KM}$ processes and $\mathrm{KM}$ enablers in universities (Figure 1). In Figure 1 all enablers and barriers are shown as enablers, since the ideal situation is that barriers can be managed and converted to enablers. More specifically, the study found that six enablers and barriers, namely, strategies and policies, organisational structures, rewards and incentives, leadership, human resources, and resources and funding, facilitate and/or inhibit knowledge creation. Four factors, rewards and incentives, culture, technology, and leadership, enable and/or hinder knowledge sharing, and knowledge transfer is facilitated and/or constrained by: strategies and policies, organisational structures, rewards and incentives, and university-industry linkages. 
The study concludes that an enabling environment can lead to knowledge creation, knowledge sharing and knowledge transfer in universities. An enabling environment embeds: a positive knowledge creation and sharing culture, awards, rewards and incentives, dedicated organisational structures, state-of-art IT infrastructure, conducive strategies and policies, visionary leadership to provide strategic direction, close university-industry linkages, qualified human resources, and adequate resources and funding. These factors help universities to contribute in national innovation systems and economic development.

Previous research on knowledge management in universities has focused mainly on academics in a single country, such as the UK or Malaysia. This research contributes to the area of public policy as well as to knowledge management practice. It does this by exploring the understanding and perceptions of senior management and academics involved in research and research management regarding the enablers and barriers to knowledge management in universities located in two countries in the sub-Saharan African region. Many of the enablers and barriers discussed in this paper are also in evidence in universities located in other countries, such as the UK and Malaysia. This study should support policy makers in other countries to further embed knowledge management in their universities.

Further research needs to be conducted into KM enablers and barriers in a wider range of contexts and countries in order to enhance understanding of role of KM in universities. For example, whilst this study covers a number of universities in two countries, it does not specifically report on the differences between the universities within a specific country. In addition, in some countries in the world, such as the United States, private universities are an important part of the university sector; it would be useful to explore whether different enablers and barriers apply in these contexts. Another potential avenue for research is to investigate the relative impact of investment in different $\mathrm{KM}$ enablers on research and innovation. Such research would offer senior university managers insights that might help them to choose where to invest their resources. In addition, future research should gather more views from academic leaders, managers, administrators and government officials. 


\section{References}

Adhikari, D.R. (2010), "Knowledge management in academic institutions", International Journal of Educational Management, Vol. 22 No. 2, pp. 94-104.

Alexandropoulou, D. A., Angelis, V. A. and Mavri, M. (2009), "Knowledge management and universities: present state and future trends", International Journal of Knowledge and Learning, Vol. 5 No.1, pp. 96-106.

Arntzen, A.A.B., Worasinchai, L. and Ribière, V.M. (2009), "An insight into knowledge management practices at Bangkok University”, Journal of Knowledge Management, Vol. 13 No. 2, pp. 127-144.

Bano, S. and Taylor, J. (2014), "Universities and the knowledge-based economy: perceptions from a developing country", Higher Education Research \& Development, Vol. 34 No. 2, pp. 242255.

Cloete, N. and Bunting, I. (2013), "Strengthening knowledge production in universities: Five South African case studies", Programme on Innovation, Universities and Research for Development (IHERD) hosted at the OECD and funded by the Swedish International Development Cooperation Agency (SIDA), pp. 1-51.

Cloete, N. and Maassen, P. (2017), Roles of universities and the African context. In: Muller, J., Cloete, P. and Van Schalkwyk, F. (eds), Castells in Africa - Universities and Development: Cape Town: African Minds. pp. 95-112.

Cranfield, D.J. and Taylor, J. (2008), “Knowledge management and universities: a UK case study”, Electronic Journal of Knowledge Management, Vol. 6 No. 2, pp. 85-100.

Eftekharzade, S.F. and Mohammadi, B. (2011), “The presentation of a suitable model for creating knowledge management in educational institutes (universities)", Procedia - Social and Behavioral Sciences, Vol. 29, pp. 1001-1011.

Fuller, D., Beynon, M. and Pickernell, D. (2019), "Indexing third stream activities in UK universities: exploring the entrepreneurial/enterprising university", Studies in Higher Education, Vol 44 No. 1, pp: 86-110.

Fullwood, R., Rowley, J. and Delbridge, R. (2013), "Knowledge sharing amongst academics in UK universities", Journal of Knowledge Management, Vol. 17 No. 1, pp. 123-136.

Fussy, D. S. (2018), "Policy directions for promoting university research in Tanzania", Studies in Higher Education, Vol 43 No. 9, pp: 1573-1585. 
Gera, R. (2012), "Bridging the gap in knowledge transfer between academia and practitioners", International Journal of Educational Management, Vol. 26 No.3, pp. 252-273.

Gertner, D., Roberts, J. and Charles, D. (2011), "University-industry collaboration: A CoPs approach to KTPs”, Journal of Knowledge Management, Vol. 15 No. 4, pp. 625-647.

Gill, A. (2009), "Knowledge management initiatives at a small university", International Journal of Educational Management, Vol. 23 No. 7, pp. 604-616.

Goh, S.K. and Sandhu, M.S. (2013), "Knowledge sharing among Malaysian academics: influence of affective commitment and trust”, Electronic Journal of Knowledge Management, Vol. 11 No. 1, pp. 38-48.

Guimon, J. (2013), "Promoting university-industry collaboration in developing countries", The Innovation Policy Platform, pp.1-11. Available at: www.innovationpolicyplatform.net (accessed 10 December 2019).

Hewitt-Dundas, N. (2012), "Research intensity and knowledge transfer activity in UK universities", Research Policy, Vol. 41 No. 2, pp. 262-275.

Hughes, A. and Kitson, M. (2012), "Pathways to impact and the strategic role of universities: new evidence on the breadth and depth of university knowledge exchange in the UK and the factors constraining its development", Cambridge Journal of Economics, Vol. 36 No. 3, pp. 723-750.

Kim, S. and Ju, B. (2008), “An analysis of faculty perceptions: attitudes toward knowledge sharing and collaboration in an academic institution", Library \& Information Science Research, Vol. 30 No. 4, pp. 282-290.

Miles, M. and Huberman, A. (1994), Qualitative Data Analysis: An Expanded Sourcebook, Sage, Beverly Hills, CA.

National Planning Commission, South Africa (2011), National Development Plan 2030: Our future make it work, Available at: https://www.gov.za/documents/national-developmentplan-2030-our-future-make-it-work [Accessed July 22, 2019]

Ojo, A. (2016), "Knowledge management in Nigerian universities: A conceptual model", Interdisciplinary Journal of Information, Knowledge, and Management, Vol. 11, pp: 331345. Retrieved from http://www.informingscience.org/Publications/3607

Ramachandran, S.D., Chong, S.-C. and Wong, K.-Y. (2013), "Knowledge management practices and enablers in public universities: a gap analysis", Campus-Wide Information Systems, Vol. 
30 No. 2, pp. 76-94.

Rivera, G. and Rivera, I. (2016), "Design, measurement and analysis of a knowledge management model in the context of a Mexican university", Innovar Open Access, Vol. 26 No. 59, pp. 2134.

Rossi, F and Rosli, A. (2014), "Indicators of university-industry knowledge transfer performance and their implication for universities: evidence from the United Kingdom", Studies in Higher Education, Vol. 40 No. 10, pp. 1970-1991.

Rowley, J. (2000), “Is universities ready for knowledge management?", International Journal of Educational Management, Vol. 14 No. 7, pp. 325-333.

Rowley, J. (2012), “Conducting research interviews”, Management Research Review, Vol. 35 No. 3/4, pp. $260-271$.

Saunders, M., Lewis, P. and Thornhill, A. (2019), Research Methods for Business Students, $8^{\text {th }}$ ed., Pearson, England.

Siadat, S.A., Hoveida, R, Abbaszadeh, M. and Moghtadaie, L. (2012), "Knowledge creation in universities and some related factors", Journal of Management Development, Vol. 31 No. 8, pp. 845-872.

Supapawawisit, B., Chandrachai, A. and Thawesaengskulthai, N. (2018), "The critical factors of research and innovation creation in public universities in Thailand", International Journal of Trade and Global Markets, Vol. 12 No. 1-2, pp. 109-117.

Tian, J., Nakamori, Y. and Wierzbicki, A.P. (2009), "Knowledge management and knowledge creation in academia: a study based on surveys in a Japanese research university", Journal of Knowledge Management, Vol. 13 No. 2, pp. 76-92.

Torre, D. L., Perez-Esparrells, C. and Casani, F. (2018), “The policy approach for the third mission of universities: The Spanish case (1983-2018)", Regional and Sectoral Economic Studies, Vol. 18 No. 1, pp. 13-33.

Trivella, L. and Dimitrios, N.K. (2015), "Knowledge Management Strategy within the Higher Education. The case of Greece", Procedia - Social and Behavioral Sciences, Vol. 175, pp. 488-495.

Twum-Darko, M. and Harker, L. A. L. (2015), "Factors influencing knowledge sharing amongst universities academics at a university in South Africa", Corporate Ownership \& Control, Vol. 12 No. 2-2, pp. 280-292. 
UNESCO. (2017), UNESCO Institute for Statistics. Available at: http://data.uis.unesco.org/ [Accessed July 30, 2019].

World Economic Forum (2019). Global Competitiveness Report. Geneva: World Economic Forum.

World Bank (2018), Sub-Saharan Africa data. Available at: https://data.worldbank.org/region/subsaharan-africa [Accessed January 6, 2020].

World Bank (2018), Available at: https://www.worldbank.org/en/news/feature/2018/12/21/yearin-review-2018-in-14-charts [Accessed January 6, 2020].

Yin, R. K. (2014), Case Study Research: Design and Methods. $5^{\text {th }}$ edition, Thousand Oaks, CA: Sage.

Zavale, N.C. and Macamo, E. (2016), "How and what knowledge do universities and academics transfer to industry in African low-income countries? Evidence from the stage of universityindustry linkages in Mozambique", International Journal of Educational Development, Vol. 49 July 2016, pp. 247-261. 
Table 2: Enablers and barriers to knowledge creation, knowledge sharing and knowledge transfer in Mauritian and South African Universities

\begin{tabular}{|c|c|c|c|c|}
\hline \multicolumn{5}{|c|}{ KNOWLEDGE CREATION } \\
\hline & \multicolumn{2}{|c|}{ MAURITIUS } & \multicolumn{2}{|c|}{ SOUTH AFRICA } \\
\hline & Enablers to $\mathrm{KC}$ & Barriers to $\mathrm{KC}$ & Enablers to $\mathrm{KC}$ & Barriers to $\mathrm{KC}$ \\
\hline $\begin{array}{l}\text { Strategies and } \\
\text { Policies }\end{array}$ & & $\begin{array}{l}\text { Lack of policies to } \\
\text { encourage and promote } \\
\text { research }\end{array}$ & $\begin{array}{l}\text { Strategies and policies } \\
\text { for } \\
\text { management }\end{array}$ & $\begin{array}{l}\text { 'Massification' of } \\
\text { universities } \\
\text { Focus on undergraduate } \\
\text { teaching } \\
\text { High student to staff ratios }\end{array}$ \\
\hline $\begin{array}{l}\text { Organisational } \\
\text { structures }\end{array}$ & $\begin{array}{l}\text { Library and digital } \\
\text { information resources }\end{array}$ & $\begin{array}{l}\text { Limited access to data and } \\
\text { databases }\end{array}$ & $\begin{array}{l}\text { Institutional repositories } \\
\text { and library services } \\
\text { Dedicated structures at } \\
\text { National and Institution } \\
\text { Level } \\
\text { Databases } \\
\text { Laboratories }\end{array}$ & \\
\hline $\begin{array}{l}\text { Rewards and } \\
\text { incentives }\end{array}$ & $\begin{array}{l}\text { Sponsorship for } \\
\text { conference attendance } \\
\text { Opportunities to } \\
\text { upgrade qualifications } \\
\text { Book purchase } \\
\text { Access to journals } \\
\text { Study leave }\end{array}$ & $\begin{array}{l}\text { Lack of reward mechanisms } \\
\text { that encourage and promote } \\
\text { research }\end{array}$ & $\begin{array}{l}\text { Awards, rewards and } \\
\text { incentives e.g. } \\
\text { researcher of the year, } \\
\text { innovator of the year. }\end{array}$ & \\
\hline Leadership & & Lack of vision & Visionary leadership & \\
\hline $\begin{array}{l}\text { Human } \\
\text { Resources }\end{array}$ & $\begin{array}{l}\text { Qualified and } \\
\text { experienced academic } \\
\text { staff in public } \\
\text { universities }\end{array}$ & & $\begin{array}{l}\text { Research capacity } \\
\text { development }\end{array}$ & $\begin{array}{l}\text { Too few academics with } \\
\text { PhDs } \\
\text { Lack of experts with IT and } \\
\text { project management skills }\end{array}$ \\
\hline
\end{tabular}




\begin{tabular}{|c|c|c|c|c|}
\hline $\begin{array}{l}\text { Resources and } \\
\text { Funding }\end{array}$ & & $\begin{array}{l}\text { Heavy workloads of } \\
\text { teaching and administrative } \\
\text { duties } \\
\text { Lack of resources and } \\
\text { funding for research }\end{array}$ & $\begin{array}{lr}\text { Funding } & \text { from } \\
\text { Government } & \text { (input } \\
\text { subsidies) } & \end{array}$ & $\begin{array}{l}\text { Heavy teaching loads } \\
\text { Competitive funding } \\
\text { environment } \\
\text { Lack of time }\end{array}$ \\
\hline \multicolumn{5}{|c|}{ KNOWLEDGE SHARING } \\
\hline & \multicolumn{2}{|l|}{ MAURITIUS } & \multicolumn{2}{|l|}{ SOUTH AFRICA } \\
\hline & Enablers to KS & Barriers to KS & Enablers to $\mathrm{KS}$ & Barriers to KS \\
\hline $\begin{array}{l}\text { Rewards and } \\
\text { incentives }\end{array}$ & & $\begin{array}{l}\text { Lack of incentives to } \\
\text { encourage knowledge } \\
\text { sharing }\end{array}$ & $\begin{array}{l}\text { Staff exchange } \\
\text { programme with } \\
\text { overseas universities } \\
\text { Calls for proposal from } \\
\text { Research Councils }\end{array}$ & Lack of incentives \\
\hline Culture & & $\begin{array}{l}\text { Lack of a knowledge } \\
\text { sharing culture } \\
\text { Promotion policy that fuels } \\
\text { individualistic and } \\
\text { competitive behaviour, and } \\
\text { mistrust } \\
\text { Few multi-disciplinary and } \\
\text { inter-institutional research } \\
\text { projects }\end{array}$ & $\begin{array}{l}\text { Multi-disciplinary and } \\
\text { transdisciplinary } \\
\text { collaborations } \\
\text { Group funding } \\
\text { opportunities } \\
\text { Communities of } \\
\text { practice Networking } \\
\text { and partnerships }\end{array}$ & $\begin{array}{l}\text { Turf protection } \\
\text { Academic culture, driving } \\
\text { individualistic behavior } \\
\text { Silo mentality } \\
\text { Competitive environment } \\
\text { due to: } \\
\text { increasing knowledge } \\
\text { production, accreditation of } \\
\text { academics by the National } \\
\text { Research Foundation, and, } \\
\text { the race for higher rankings }\end{array}$ \\
\hline Technology & $\begin{array}{l}\text { Good IT infrastructure } \\
\text { Connectivity } \\
\text { Intranet } \\
\text { Email }\end{array}$ & & $\begin{array}{l}\text { Institutional repository } \\
\text { Open access platform } \\
\text { E-mail }\end{array}$ & \\
\hline Leadership & & Frequent leadership changes & & \\
\hline \multicolumn{5}{|c|}{ KNOWLEDGE TRANSFER } \\
\hline & \multicolumn{2}{|c|}{ MAURITIUS } & \multicolumn{2}{|c|}{ SOUTH AFRICA } \\
\hline
\end{tabular}




\begin{tabular}{|l|l|l|l|l|}
\hline $\begin{array}{l}\text { Strategies and } \\
\text { policies }\end{array}$ & Enablers to KT & Barriers to KT & Enablers to KT & Barriers to KT \\
\hline $\begin{array}{l}\text { Organisational } \\
\text { structures }\end{array}$ & $\begin{array}{l}\text { Lack of IP } \\
\text { strategies/policies }\end{array}$ & $\begin{array}{l}\text { IP Act (2008) } \\
\text { IPnowledge transfer }\end{array}$ \\
\hline $\begin{array}{l}\text { Rewards and } \\
\text { incentives }\end{array}$ & $\begin{array}{l}\text { Fortal } \\
\text { Research repository } \\
\text { consultancy work } \\
\text { Reduced teaching load } \\
\text { in a few private } \\
\text { universities }\end{array}$ & $\begin{array}{l}\text { Technology Transfer } \\
\text { Office/IP Units } \\
\text { Instruments for } \\
\text { university-industry } \\
\text { linkages }\end{array}$ & $\begin{array}{l}\text { Lack of information on } \\
\text { patenting process }\end{array}$ \\
\hline $\begin{array}{l}\text { University- } \\
\text { industry } \\
\text { linkages }\end{array}$ & & $\begin{array}{l}\text { Weak industry-academicentives } \\
\text { linkages }\end{array}$ & & \\
\hline
\end{tabular}




\section{KM ENABLERS}

KM PROCESSES

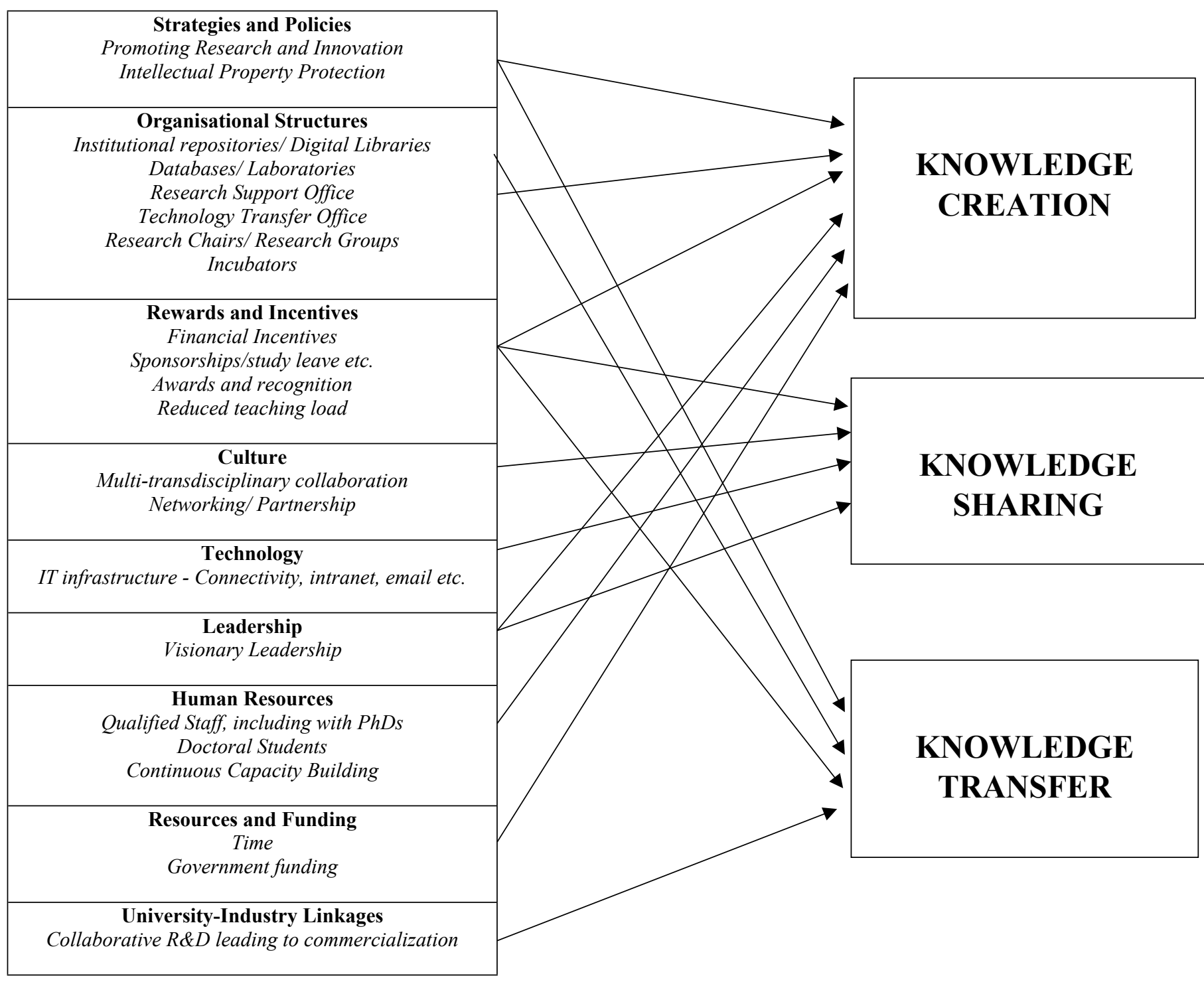

Figure 1: Framework for Enabling Knowledge Management in Universities 